\title{
RESGATE HISTÓRICO COMO INSTRUMENTO DE AVALIAÇÃO DA DEGRADAÇÃO AMBIENTAL EM BACIA HIDROGRÁFICA COSTEIRA
}

\author{
Letícia Rabelo $^{1}$ \\ Paulo Ricardo Schwingel ${ }^{2}$
}

Resumo: O objetivo do presente trabalho foi avaliar a degradação ambiental na bacia hidrográfica do rio Camboriú (SC) a partir de resgate histórico como instrumento. Esse estudo foi baseado em relatos de memórias obtidos por entrevista com moradores, no período 1950-2010. Foram identificados usos relatados, usos perdidos e características da bacia. Até a década de 1970, apesar das modificações sofridas, a bacia permanecia sem degradação ambiental. Na década de 1980, a degradação dos recursos hídricos ficou evidente. Os relatos de memórias mostraram-se um instrumento robusto para a identificação de processos de degradação ambiental.

Palavras-chave: Relatos de memórias. Pressão urbana. História ambiental. Recursos hídricos. Rio Camboriú.

\section{HISTORICAL RESCUE AS EVALUATION TOOL OF ENVIRONMENTAL DEGRADATION IN COASTAL RIVER BASIN}

Abstract: The objective of the present work was to evaluate the environmental degradation in the Camboriú River Basin (SC) from historical rescue as an instrument. This study was based reports of memories obtained by interview with residents, in the period 1950-2010. Reported uses, lost uses and characteristics of the basin were identified. Until the 1970s, despite the modifications suffered, the basin remained without any apparent environmental degradation. In the 1980s, the degradation of water resources was evidenced. Memories reports are a robust tool for the identification of processes of environmental degradation.

Keywords: Reports of memories. Urban pressure. Environmental history. Water resources. Camboriú River.

\section{RESCATE HISTÓRICO COMO INSTRUMENTO DE EVALUACIÓN DE LA DEGRADACIÓN AMBIENTAL EN CUENCA HIDROGRÁFICA COSTERA}

Resumen: El objetivo del presente trabajo fue evaluar la degradación ambiental en la cuenca hidrográfica del río Camboriú (SC) a partir de rescate histórico como instrumento. Este estudio fue basado en relatos de memorias obtenidas por entrevista con moradores, en el período 1950-2010. Se identificaron usos relatados, usos perdidos y características de la cuenca. Hasta la década de 1970, a pesar de las modificaciones sufridas, la cuenca, permanecía sin degradación ambiental aparente. En la década de 1980, la degradación de los recursos hídricos fue evidenciada. Los relatos de memorias se mostraron un instrumento robusto para la identificación de procesos de degradación ambiental.

Palabras clave: Relatos de memorias. Presión urbana. Historia ambiental. Recursos hídricos. Río Camboriú.

\footnotetext{
${ }^{1}$ Instituto Federal Catarinense, Camboriú, Brasil, email@email.br, http://orcid.org/0000-0002-77493451

${ }^{2}$ Univali, Escola do Mar, Ciência e Tecnologia, Itajaí, Brasil, email@email.br, http://orcid.org/00000002-1810-9528
} 


\section{Introdução}

A área total de paisagens que possuem atributos ambientais foi bastante reduzida a partir da segunda metade do século 20 em todo o mundo. Por este motivo, a preservação de paisagens preservadas é valiosa não somente pela herança cultural, mas também pela qualidade de suas belezas cênicas e ambientais (Sklenicka et al., 2017). As noções de equilíbrio e harmonia atualmente são muito discutidas, tanto nas relações ecológicas da própria natureza quanto nas relações entre os seres humanos e a natureza (Faria et al., 2005; Pott e Estrela, 2017). A ideia da natureza intocada, que nunca teria sido transformada por agentes naturais ou antrópicos é inexistente. A desmistificação é imprescindível para se analisar o lugar das populações e seus conhecimentos na preservação do ambiente. Uma grande parte das práticas tradicionais de manejo e de conhecimento sobre a mata, os rios, os lagos e o mar têm influência dos saberes e práticas dos povos, que foram transmitidos através de gerações de forma oral (Diegues, 1998; Serpa, 2015; Duval, 2017).

A memória das pessoas pode revelar riquezas e diversidades que não são conhecidas e que muitas vezes podem ajudar com relatos importantes sobre a história de um ambiente. $\mathrm{O}$ fato de as pessoas mais idosas terem chegado antes das cidades se expandirem, ajuda os pesquisadores a saber como era o ambiente antes da urbanização de determinado local (Almeida, 2003). De acordo com Devos et al. (2010), o levantamento das memórias é importante no processo de compreensão da inserção dos territórios urbanos na bacia hidrográfica e suas modificações ao longo do tempo. A investigação da memória ambiental é uma forma de compreender as transformações na paisagem e diversidade de itinerários da sua população, refletindo sobre os arranjos entre a natureza e as cidades (McNeill, 2003; Devos et al., 2010; Villaseñor, 2017).

Para Pollak (1992), não há diferença fundamental entre fonte escrita e fonte oral, pois se a memória é socialmente construída, toda documentação também o é. A crítica da fonte, tal como o pesquisador aprende a fazer, deve ser aplicada a todos os tipos de fontes. Nesse ponto de vista, a fonte oral é exatamente comparável à fonte escrita, nenhuma delas pode ser tomada tal e qual ela se apresenta. A história oficial ou tradicional nos traz dados importantes da ocupação de regiões, por outro lado, acaba por apagar o cotidiano, os modos de fazer e as histórias locais (Halbwachs, 2006). Assim, a história oral pode ser resgatada por meio de relatos de 
antigos moradores do local, valorizando e preservando essas narrativas e o patrimônio histórico e ambiental (Montalba et al., 2017). Cabe, portanto, encontrar e abrir canais de participação para a manifestação dos desejos de evitar a perda do passado (Moraes e Tricário, 2006).

De acordo com Lopes e Nodari (2012), em estudo de levantamento de relatos históricos da Lagoa de Sombrio, localizada em Santa Catarina, a memória dos moradores sobre o processo de degradação do local pode oferecer uma percepção da paisagem e suas transformações. Segundo os autores, as primeiras discussões e os primeiros estudos sobre a recuperação ambiental dessa lagoa não levaram em consideração o conhecimento tradicional que esses indivíduos tinham a oferecer. Tão importante quanto aos atributos geográficos e físicos que dão feições ambientais prévias a um lugar, a memória ambiental e social é um par indissociável (Camargo, 2016; Sartori e Valencio, 2016; Alanoca e Apaza, 2018). No levantamento da percepção de moradores sobre a qualidade da água de um rio urbano na região de Lages (SC) ficou evidenciado pelos entrevistados a necessidade da ação do poder público para melhorar a situação (Antunes et al., 2014).

A bacia hidrográfica do rio Camboriú, formada pelos municípios de Camboriú e de Balneário Camboriú, é atualmente uma das mais pressionadas do litoral do Estado de Santa Catarina (Brasil) em termos de uso e ocupação do solo (Silva, 2015; Granemann, 2014; Padilha, 2013). A pressão urbana é uma realidade nas últimas décadas nos dois municípios e, em especial no município de Balneário Camboriú, onde o processo de urbanização caminhou em função do mercado turístico, dando via a uma intensa ocupação da planície costeira, penalizando a população nativa e privando-a de seus espaços, paisagens, tradições e qualidade de vida (Moraes e Tricário, 2006; Anjos et al., 2009). Tomadores de decisão veem a superexploração do turismo massificado e a verticalização desenfreada como modelo de desenvolvimento bem-sucedido, ignorando os impactos sociais e ambientais que esse tipo de urbanização carrega (Moraes e Tricário, 2006; Anjos et al., 2009; Brognoli, 2010).

Essa bacia sofreu diversas modificações ao longo do tempo, que, entre outros fatores, causou a degradação ambiental do rio Camboriú (Urban, 2008; Antunes et al., 2007). De acordo com o IBGE (2017), de 1970 até a estimativa populacional para 2016, o crescimento em Balneário Camboriú foi de aproximadamente $1.215 \%$ e o de Camboriú foi de $776 \%$, em 46 anos, e continua num crescimento ascendente, 
aumentando a pressão de fatores estressantes sobre a bacia hidrográfica. Assim, para o entendimento desse processo, este trabalho pretendeu realizar o resgate histórico da degradação ambiental do rio Camboriú. Para tanto, foi realizado um estudo baseado na história escrita e relatos de memórias de moradores há mais de 40 anos na bacia.

\section{Metodologia}

Área de Estudo

A área de estudo deste trabalho compreendeu a bacia hidrográfica do rio Camboriú (SC). As entrevistas para o levantamento dos relatos de memórias foram realizadas nos cursos superior, médio e inferior do rio. O curso superior é a parte mais alta do rio, próximo às nascentes e possui um declive acentuado. $\mathrm{O}$ curso médio possui um declive menos acentuado, com correntes menos velozes. $O$ curso inferior é a parte mais baixa do rio, próxima à foz e possui pouca declividade e correntes lentas. No curso superior, as entrevistas foram realizadas na região da Limeira, Macacos e Caetés; no curso médio, na região do Braço, Rio Canoas, Morretes, Santa Regina e o Centro de Camboriú; e no curso inferior, localizados mais próximos à foz, no Rio Pequeno, Rio Peroba, Barra e Centro de Balneário Camboriú (Figura 1). 


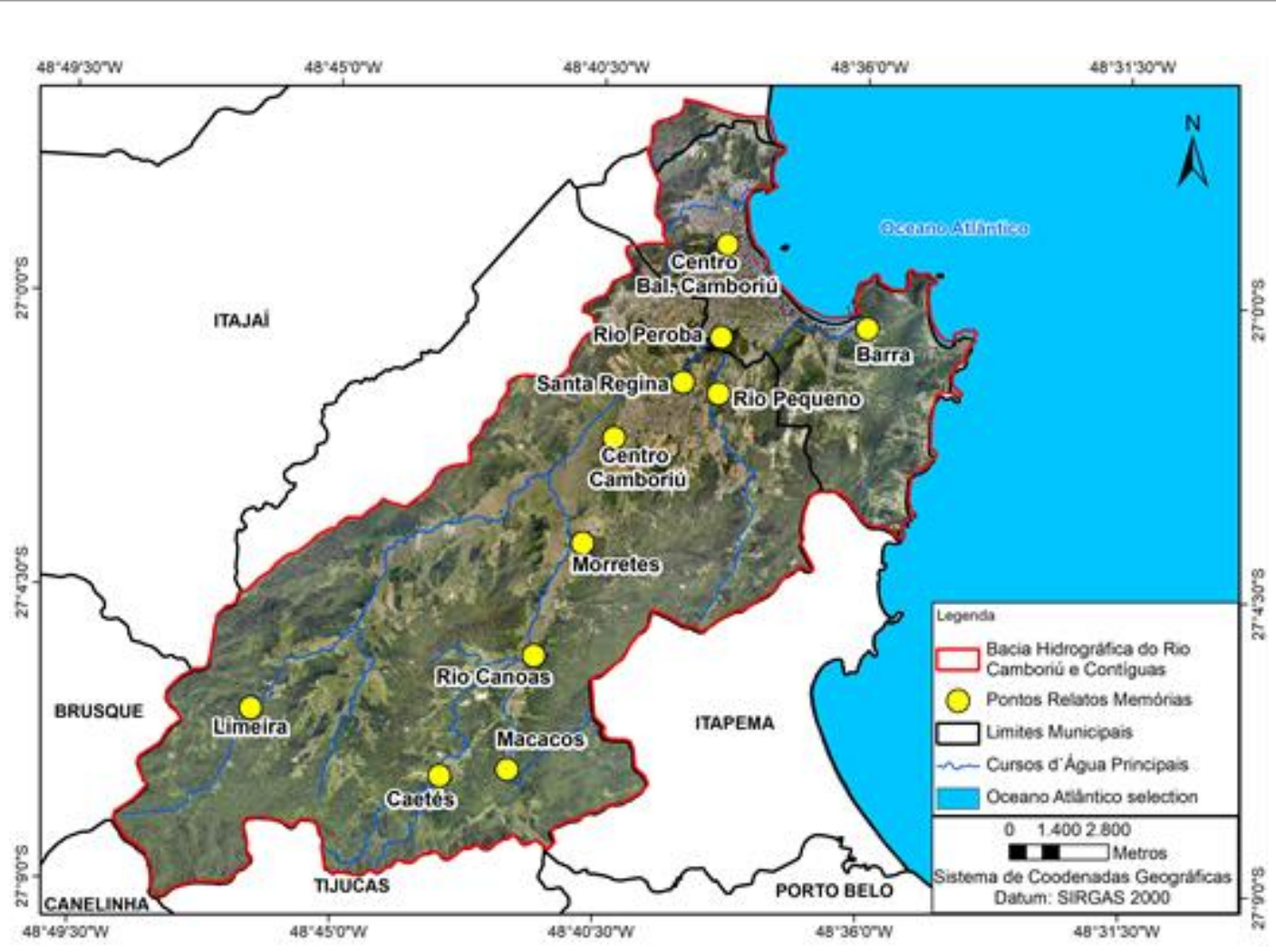

Figura 1. Localidades das entrevistas realizadas com moradores da bacia hidrográfica do rio Camboriú (SC).

Coleta e sistematização dos dados

Aspectos relacionados à história escrita da degradação ambiental da bacia hidrográfica do rio Camboriú, estudada com o objetivo de aprofundar conhecimentos e compará-los aos relatos, foram baseados nos livros de Corrêa (1985) e Rebelo (1997), pois estes são os únicos autores com livros publicados sobre a história da região estudada. A história escrita foi levantada para que fosse posteriormente comparada à história oral. A história oral foi compilada a partir de entrevistas utilizadas como instrumento de avaliação dos impactos ambientais sobre os recursos hídricos nas localidades do curso superior, médio e inferior do rio Camboriú. O levantamento dos relatos se baseou em metodologia estabelecida por Almeida (2003), García (2017) e Aparicio e Canales (2017), autores que trabalharam com relatos da população local, em especial antigos moradores das localidades estudadas, para obter uma maior fidelidade de informações sobre modificações e intervenções.

As entrevistas proporcionaram às pessoas lembranças das intervenções realizadas na área ao longo do tempo, sendo aplicadas a antigos moradores da bacia, que tenham tido uma relação de proximidade com o rio Camboriú a partir de antes de 1950. Um total de 30 entrevistas foram realizadas, e os entrevistados foram 
encontrados por meio de contatos e indicações pessoais, pois houve dificuldade em encontrar antigos moradores na bacia. As informações obtidas nos questionários foram confrontadas com estudos pretéritos. Um total de 30 entrevistas foram realizadas, incluindo 10 moradores do curso superior do rio, 12 do curso médio e 8 do inferior. No curso superior do rio foram realizadas entrevistas nas localidades Limeira, Macacos e Caetés. No curso médio da bacia hidrográfica do rio Camboriú foram realizadas entrevistas em quatro localidades: Braço, rio Canoas, Morretes e Santa Regina. Na localidade mais próxima a foz, o curso inferior, foram realizadas entrevistas nas comunidades do Rio Peroba, Rio Pequeno, Barra e Centro de Balneário Camboriú.

Para que as entrevistas fossem realizadas foi necessária a autorização, por meio de um termo de consentimento livre e esclarecido (TCLE) exigido pelo comitê de ética, do entrevistado. No momento da entrevista, foi preenchida uma tabela discriminando os usos relatados, incluindo aqueles perdidos para cada década (antes de 1950, 1950, 1960, 1970, 1980, 1990, 2000 até a década atual), de cada atividade: pesca, agricultura, uso doméstico, esgoto, banho, navegação, vegetação e outras, conforme os relatos. As entrevistas foram gravadas em áudio ou vídeo, para serem ouvidas posteriormente e revistos detalhes que não tinham sido identificados.

Posteriormente, os dados brutos foram agrupados em outra tabela a fim de relacionar os usos relatados, perdidos e as características de cada uso (pesca, agricultura, uso doméstico, esgoto, banho, navegação, vegetação e outras, conforme os relatos), de antes de 1950, de 1950 a 1970, de 1980 a 1990 e de 2000 até os dias atuais em cada curso do rio.

\section{Resultados e Discussão}

História da degradação ambiental na Bacia hidrográfica do rio Camboriú

A bacia hidrográfica do rio Camboriú (BHRC) teve os primeiros registros de ocupações advindas de populações sambaquianas. Essas populações compunham grupos pré-históricos que habitaram a costa sudeste e sul do Brasil durante a segunda metade do Holoceno médio, aproximadamente entre 6500 e 800 anos antes do presente (Okumura, 2013). Em Santa Catarina, as evidências dessas 
povoações foram inicialmente escavadas pelo Padre João Alfredo Rohr, como aponta Corrêa (1985).

Após os sambaquianos, os habitantes da bacia, à época da chegada dos colonizadores europeus, eram os indígenas. Diversos nomes de locais são de origem indígena, tanto o nome Camboriú, como Ariribá, Canhanduba, Taquaras, Caetés, entre outros. O nome do município foi batizado com o mesmo nome do rio, que inicialmente era Camboriguassu, ou Camboriasu, sendo que em tupi-guarani, Cambori significa robalo e Guassu significa grande (Corrêa, 1985, 2012), entre outras teorias, a maioria das quais sem ter sido publicadas.

De acordo com Corrêa (1985), os índios que habitavam o litoral pertenciam à tribo Carijó, sendo que no interior do município de Camboriú habitavam os Botocudos, do grupo Tapuia, popularmente chamado de bugre, que era arisco e defensor de suas terras, sendo atualmente conhecidos por Xoklengs (Serpa, 2015). Esses índios viviam de maneira nômade na área entre o planalto e o litoral. No século XVIII, viviam da caça, da coleta de mel e do pinhão retirado das araucárias durante o inverno no planalto e no verão migravam para os vales reunindo-se em grandes acampamentos (Serpa, 2015).

Os colonizadores chegaram com o principal objetivo de desenvolver a agricultura e para isso desmatavam as florestas que davam sustento aos indígenas. Os troncos de árvores cortadas eram transportados no leito dos rios em toda a bacia. Durante os séculos XVIII e XIX, assim como o corte de florestas nativas para uso da madeira foi um grande degradador da qualidade ambiental da bacia hidrográfica do rio Camboriú, as folhas e cascas das árvores dos manguezais, em especial a espécie mangue-vermelho (Rizophora mangle), eram removidas e vendidas a curtumes e utilizadas para conservar o couro pelo tanino que possuem (Rebelo, 1997). Por outro lado, há evidências de preocupação com a degradação ambiental do rio Camboriú desde o início do século $\mathrm{XX}$. O primeiro código de posturas foi estabelecido em 1903, no qual foi estabelecido multa para quem poluísse rios e fontes ou jogasse lixo nas ruas do município (Rebelo, 1997).

Um fato que relata um exemplo de degradação ambiental de origem natural foi a invasão da praia por gafanhotos. Por volta de 1912, a praia de Balneário Camboriú tinha uma grande plantação de agave (Agrave rigida), popularmente chamada de sisal ou pita. Esta planta, importada da Índia e da África, era utilizada para fabricação de cordas. Porém, em 1913, uma nuvem de gafanhotos (Schistocerca paranensis) originados dos chacos bolivianos, comeu toda a 
vegetação da praia, até o limo das pedras da llha das Cabras, localizada na praia central de Balneário Camboriú (Corrêa, 1985).

No final do século XIX, a navegabilidade do rio Camboriú era uma necessidade para o transporte e para a manutenção econômica da bacia. Havia dois portos no rio, que escoavam os produtos minerais, silviculturais e agrícolas de Camboriú e recebiam produtos de outras regiões do estado e até de outras localidades do país (Corrêa, 1985). Uma evidência da necessidade de se manter o rio navegável foi quando, em 1894, o Governador Hercílio Luz enviou uma verba a Camboriú para o conserto da foz do rio, o qual, devido a uma grande enchente, estava com uma segunda foz e bastante assoreado. Isso havia tornado o rio inavegável e isolava a população de Camboriú, que possuía somente a saída pelo rio ou por picadas no meio da mata (Corrêa, 1985). Na época, Camboriú já era considerado um município em ampla expansão no plantio do café (Corrêa, 1985), sendo imprescindível o escoamento dessa produção para outras localidades.

Ainda no início do século $\mathrm{XX}$, o rio Camboriú continuou sendo bastante utilizado para navegação e continuou tendo os dois portos, sendo eles, o Cais Três Ranchos, localizado no Rio Pequeno (bairro Barranco) e o porto do Mercado Público de Camboriú. Nestes portos, eram atracadas as embarcações carregadas de mercadorias que chegavam e saiam carregando os produtos agrícolas, madeira, mármores, rochas e carne produzidos em Camboriú. O Cais Três Ranchos foi maior que o porto de Itajaí (SC) por muitas décadas (Rebelo, 1997).

Durante esta década de 1920, o município estava em plena expansão econômica, tendo sido o maior exportador de café do estado de Santa Catarina. $\mathrm{Na}$ crise de 1929, os Estados Unidos, maior comprador de café, pararam de importar o produto (Ribeiro, 2015; Galeano, 2017). Além disso, com a grande safra de café daquele ano e o golpe de 1930 no Brasil, a crise se acentua e provoca o desemprego em massa, forçando a saída de muitas pessoas das zonas rurais, pois a revolução industrial está a pleno vapor. Nesta época, muitas pessoas saíram das zonas rurais de Camboriú e migraram para outros municípios em busca de melhores oportunidades (Rebelo, 1997). Esse êxodo rural foi continuado até a década de 1980 (Tabela 1).

Tabela 1. Cronologia de usos e eventos na bacia hidrográfica do rio Camboriú, SC, entre os séculos XVIII e XXI.

\begin{tabular}{l|l|l|l|l|l|l|l}
\hline \multirow{2}{*}{ Período } & \multicolumn{5}{|c}{ Usos/Eventos } \\
\cline { 2 - 6 } & Portos & Desmatamento & Navegação & $\begin{array}{l}\text { Agricultura } \\
\text { familiar }\end{array}$ & $\begin{array}{l}\text { Legislação } \\
\text { Ambiental }\end{array}$ & $\begin{array}{l}\text { Urbanização } \\
\text { intensa }\end{array}$ & $\begin{array}{l}\text { Retorno } \\
\text { zona rural }\end{array}$ \\
\hline $\begin{array}{l}\text { Séc. XVIII e e } \\
\text { XIX }\end{array}$ & $\begin{array}{l}\text { - Três Ranchos } \\
\text { - Mercado } \\
\text { Público }\end{array}$ & $\begin{array}{l}\text { - Árvores } \\
\text { nativas }\end{array}$ & $\begin{array}{l}\text { - Barcos à } \\
\text { vela }\end{array}$ & $\begin{array}{l}\text { - Diversas } \\
\text { culturas }\end{array}$ & & \\
\hline
\end{tabular}




\begin{tabular}{|c|c|c|c|c|c|c|c|c|}
\hline $\begin{array}{l}\text { Séc. } \\
\text { XX }\end{array}$ & XIX e & $\begin{array}{l}\text { - Três Ranchos } \\
\text { - Mercado } \\
\text { Público }\end{array}$ & $\begin{array}{l}\text { - Árvores } \\
\text { nativas }\end{array}$ & $\begin{array}{l}\text { - Barcos à } \\
\text { vela }\end{array}$ & $\begin{array}{l}\text { - Diversas } \\
\text { culturas }\end{array}$ & & & \\
\hline \multirow{4}{*}{$\begin{array}{l}\text { Séc. } \\
X X \\
\text { e } \\
X X I\end{array}$} & $\begin{array}{l}1900 \\
a \\
1950\end{array}$ & $\begin{array}{l}\text { - Três Ranchos } \\
\text { - Mercado } \\
\text { Público }\end{array}$ & $\begin{array}{l}\text { - Árvores } \\
\text { nativas }\end{array}$ & $\begin{array}{l}\text { - Barcos à } \\
\text { vela }\end{array}$ & $\begin{array}{l}\text { - Diversas } \\
\text { culturas } \\
\text { - Êxodo rural }\end{array}$ & $\begin{array}{l}\text { - Código de } \\
\text { posturas (1903) } \\
\text { - Proteção de } \\
\text { 100m da orla } \\
(1936)\end{array}$ & & \\
\hline & $\begin{array}{l}1950 \\
a \\
1970 \\
\end{array}$ & & $\begin{array}{l}\text { - Árvores } \\
\text { nativas } \\
\text { - Corte de } \\
\text { eucalipto }\end{array}$ & $\begin{array}{l}\text { - Barcos à } \\
\text { vela } \\
\text { - Lanchas }\end{array}$ & $\begin{array}{l}\text { - Diversas } \\
\text { culturas } \\
\text { - Rizicultura } \\
\text { - Exxodo rural } \\
\end{array}$ & & & \\
\hline & $\begin{array}{l}1980 \\
a \\
1990 \\
\end{array}$ & & & & $\begin{array}{l}\text { - Rizicultura } \\
\text { - Êxodo rural }\end{array}$ & & $\begin{array}{l}\text { - Urbanização } \\
\text { de Balneário } \\
\text { Camboriú }\end{array}$ & \\
\hline & $\begin{array}{l}2000 \\
\text { até } \\
\text { hoje } \\
\end{array}$ & & & & & & $\begin{array}{l}\text { - Urbanização } \\
\text { de Balneário } \\
\text { Camboriú e } \\
\text { Camboriú } \\
\end{array}$ & - Sitiantes \\
\hline
\end{tabular}

Fonte: baseado em Corrêa (1985), Rebelo (1997), IBGE (2017) e relatos de memórias.

Com relação a possível degradação ambiental no rio Camboriú, na década de 1950, houve missões americanas na área da saúde em Camboriú, que introduziram inseticidas químicos para sanear a população e as residências. Foram aplicados o alarém (cloroquina) contra a malária, o quinino como vermífugo, o DDT (diclorodifeniltricloroetano) e o BHC (hexaclorobenzeno) (este conhecido como pó de gafanhoto) e foi realizada a dedetização obrigatória das residências (Rebelo, 1997). Esses produtos químicos perigosos causam impactos ambientais ao ar, ao solo, à água e podem lixiviar para o rio. É ainda importante salientar que desde a década de 1970 esses inseticidas são de uso proibido em diversas partes do mundo.

No ano de 1964, Balneário Camboriú se torna município, sendo separado de Camboriú. Na década de 1970, a pavimentação da rodovia BR101 foi um fato que modificou a realidade da região. Atrelada à melhoria da economia, ocorreu um intenso processo de artificialização de Balneário Camboriú, sendo a rodovia o ponto de partida para o entendimento do processo da acentuada urbanização influenciada pela tendência mundial de ocupação massiva (Reis, 2008; Skalee e Reis, 2008; Piatto e Polette, 2012). Essa urbanização acentuada de Balneário Camboriú influenciou a urbanização do município de Camboriú e o retorno as zonas rurais a partir da década de 2000.

Relatos de memórias

Os relatos de memórias foram narrativas apresentadas pelos entrevistados sobre lembranças de mudanças na bacia hidrográfica do rio Camboriú ao longo das décadas, especialmente aquelas associadas a degradação ambiental. 


\section{Curso superior}

De acordo com os relatos, nas décadas de 1950 e 1960, o uso doméstico da água no curso superior do rio Camboriú estava associado a lavação de roupas e louças, bem como ao banho de higiene, em cachoeiras ou direto no rio. A coleta de água do rio e de nascentes em latas ou baldes perdurou até a década de 1970. Nas décadas seguintes (1970 e 1980) foram construídos poços e a água das nascentes foi encanada para o abastecimento das casas, uso que permanece atualmente (Tabela 2).

Tabela 2. Cronologia de usos relatados, usos perdidos e características do curso superior da bacia hidrográfica do rio Camboriú.

\begin{tabular}{|c|c|c|c|}
\hline Período & Usos relatados & Usos perdidos & Características \\
\hline $\begin{array}{l}\text { Antes } \\
1950\end{array}$ & $\begin{array}{l}\text { - Irrigação } \\
\text { - Pesca (lambari, traíra, jundiá, saguarú, } \\
\text { lampião, cascudo, cará, piava, tajabecu e ainda } \\
\text { camarão branco) } \\
\text { - Banho higiênico } \\
\text { - Uso doméstico } \\
\text { - Despejo de esgoto }\end{array}$ & & $\begin{array}{l}\text { - Corte de madeira nativa } \\
\text { - Fauna (tatu, quati, cotia, paca, } \\
\text { veado, macaco, aracuã, macuco, } \\
\text { jacupema e tucano) e flora } \\
\text { abundantes } \\
\text { - Caça } \\
\text { - Rio mais largo e profundo }(2 \mathrm{~m})\end{array}$ \\
\hline 1950 a 1970 & $\begin{array}{l}\text { - Irrigação } \\
\text { - Pesca (lambari, traíra, jundiá, saguarú, } \\
\text { lampião, cascudo, cará, piava, tajabecu e ainda } \\
\text { camarão branco) } \\
\text { - Nado } \\
\text { - Uso doméstico } \\
\text { - Despejo de esgoto }\end{array}$ & - Banho higiênico & $\begin{array}{l}\text { - Corte de madeira nativa } \\
\text { - Fauna (tatu, quati, cotia, paca, } \\
\text { veado, macaco, aracuã, macuco, } \\
\text { jacupema e tucano) e flora } \\
\text { abundantes } \\
\text { - Caça reduzida } \\
\text { - Rio mais largo e volumoso ( } 2 \\
\text { m) }\end{array}$ \\
\hline 1980 a 1990 & $\begin{array}{l}\text { - Irrigação } \\
\text { - Despejo de esgoto (fossa) }\end{array}$ & $\begin{array}{l}\text { - Pesca } \\
\text { - Nado } \\
\text { - Uso doméstico } \\
\text { - Extinção da } \\
\text { fauna e da flora }\end{array}$ & $\begin{array}{l}\text { - Regeneração florestal } \\
\text { - Retificações no rio } \\
\text { - } 30 \text { cm profundidade } \\
\text { - Aumento dos insetos }\end{array}$ \\
\hline 2000 até hoje & $\begin{array}{l}\text { - Irrigação } \\
\text { - Despejo de esgoto (fossa) }\end{array}$ & $\begin{array}{l}\text { - Pesca } \\
\text { - Nado } \\
\text { - Uso doméstico }\end{array}$ & \\
\hline
\end{tabular}

De acordo com os relatos, nas décadas de 1950 e 1960, o uso doméstico da água no curso superior do rio Camboriú estava associado a lavação de roupas e louças, bem como ao banho de higiene, em cachoeiras ou direto no rio. Segundo as entrevistas, com relação ao esgoto doméstico, entre as décadas de 1950 a 1980 o mesmo não era tratado. Somente a partir da década de 1990 foram construídos banheiros e fossas em algumas casas. Desde a década de 2000, todas as casas possuem banheiro e fossa (Tabela 2). Apesar do tratamento por fossa não possuir eficiência adequada, o rio nessa área ainda possui capacidade de diluição dos efluentes domésticos (Antunes et al., 2007; Urban, 2008; Webber, 2010).

De acordo com as narrativas, o banho recreativo de rio era pouco utilizado na década de 1950 devido à grande profundidade do rio, que chegava até mais de 2 metros em alguns locais, além da largura e correnteza da água. A partir da década de 1980 a lâmina d'água foi diminuindo, chegando a menos de $30 \mathrm{~cm}$ em diferentes locais, reduzindo o banho, como foi relatado para a localidade de Caetés. A partir da 
década de 1990, foram explorados o ecoturismo e o lazer em cachoeiras localizadas no curso superior, uso que continua até hoje. Em geral, atualmente o rio no curso superior encontra-se bastante assoreado, tendo sido inclusive relatado que afluentes secaram devido ao desmatamento.

Com relação à pesca, foi relatado que de 1950 a 1970 havia maior abundância de peixes nos rios, pescava-se mais, sendo espécies de peixes existentes: lambari, traíra, jundiá, saguarú, lampião, cascudo, cará, piava, tajabecu, e ainda camarão-branco. A pesca era realizada com balaio, rede, caniço e tarrafa. A partir do final da década de 1970, percebe-se a redução dos peixes e da pesca, até se tornar pouco significativa na década de 1990. Ao mesmo tempo, na década de 1980 se percebe o aumento de insetos.

Os entrevistados relataram que a agricultura familiar no curso superior foi bastante desenvolvida nas décadas de 1950 e 1960, época em que o curso superior possuía uma população de moradores. As espécies cultivadas eram: café sombreado, a mandioca, banana, cana, feijão, milho, amendoim, maracujá e olericultura. As plantações orgânicas e cultivos eram agroflorestais, sendo que, ao mesmo tempo, ocorria o corte de árvores nativas para venda. Devido ao êxodo rural a partir de 1960, o desenvolvimento da agricultura no local começa a diminuir. Por volta de 1970, foi iniciado o plantio de fumo na região, com a utilização de agrotóxicos, até a década de 1980. Esta atividade foi relacionada pelos entrevistados à problemas de saúde, em especial de visão e rins. A partir desta década, a agricultura familiar inicia um processo de redução devido ao êxodo rural.

Segundo os relatos, nas décadas de 1950 a 1970, a população em todo o curso superior do rio Camboriú, era maior que hoje e, com o êxodo rural, essa população foi reduzida até a década de 1990. Sendo que a população da zona rural do município passou de aproximadamente 8.000 pessoas no Censo do ano 1970, chegando a aproximadamente 2.000 pessoas no Censo do ano 2000 (IBGE, 2017). A partir da virada do século, as pessoas começaram a retornar ao campo, porém com parcelamentos e loteamentos irregulares e um crescimento desordenado. $O$ estudo de Silva (2015) mostra que nas regiões mais altas do rio houve um crescimento na urbanização a partir de 2004. De acordo com Cechet (2015), a zona rural do município de Camboriú vem sofrendo mudanças durante os últimos anos no seu parcelamento do solo, com a venda de pequenas áreas de terra. As entrevistas evidenciaram que a urbanização sem planejamento, causada pelo êxodo urbano e 
pela gentrificação, resulta no uso do campo como dormitório ou casa de final de semana, pouco agregando a comunidade local (Skalee e Reis, 2008).

Além desse fenômeno, é importante salientar a pequena população jovem que compõe a zona rural da bacia. De acordo com o estudo realizado por Cechet (2015), 64,7\% dos seus entrevistados mostram uma população adulta e idosa, que, segundo a pesquisadora é resultado do êxodo rural dos jovens. Esses dados foram corroborados pelo presente estudo que obteve relatos nas entrevistas sobre a carência de políticas públicas que incentivem aos produtores rurais uma atividade econômica mais produtiva, que possa influenciar no desenvolvimento econômico do município, bem como na conservação dos recursos naturais, na qualidade de vida da comunidade de toda a zona rural e fomento ao turismo rural.

De acordo com os relatos, a caça é uma realidade nas regiões do curso superior do rio Camboriú. Na década de 1950, se caçava tatu, quati, cotia, paca, veado, macaco, além de aves (aracuã, macuco, jacupema e tucano). A partir das décadas de 1970 e 1980, a caça perdeu a intensidade devido à proibição. Relatos afirmam que vários animais foram extintos, mas ainda se caça quati, cotia e tatu.

Segundo os relatos, até a década de 1950, devido aos plantios nos morros e ao corte de árvores, havia pouca mata nativa. As árvores cortadas eram transportadas no leito do rio com os troncos amarrados uns aos outros. A partir da década de 1960, iniciou-se o plantio de espécies exóticas para corte, como o Eucalipto. Entretanto, devido à intensificação do êxodo rural, observa-se uma regeneração natural gradativa da floresta na década de 1970, inclusive associada a proibições do corte de espécies nativas. Porém, entrevistados relatam a extinção de diversas espécies da flora a partir da década de 1970.

As entrevistas apontaram uma intervenção importante feita no rio dos Macacos e também no rio Camboriú, tanto no curso superior como no médio. Esta intervenção foi a retificação do rio na década de 1980. No ano de 1983, ocorreu uma grande enchente e a região foi bastante afetada, pois casas se localizavam muito próximas às margens. Sendo assim, acreditava-se que a retificação do rio seria a única solução para o problema, sendo a mesma realizada nos anos seguintes por intervenção de órgão públicos. Os moradores identificaram que a partir dessas modificações os peixes do rio sumiram. Os moradores acreditam que curvas do rio servem de refúgios para diversas espécies e facilitam a obtenção de alimentação para os peixes. Brocaneli e Stuermer (2008) mostram que retificações não são uma solução adequada para a redução das enchentes pois elas diminuem o tempo de 
retenção da água na bacia e aumentam a velocidade da água, podendo causar danos ainda maiores e posterior assoreamento. Rodrigues et al. (2010) complementam que a retificação provoca redução da área de drenagem das bacias hidrográficas o que provoca uma redução drástica na densidade e diversidade de espécies aquáticas.

\section{Curso médio}

Esta é uma região de planície, na qual a principal atividade econômica desenvolvida é a rizicultura. Também foram realizadas entrevistas no Centro de Camboriú, localizado na zona urbana do município. Na divisa da região rural com áreas urbanizadas, a rizicultura e área alagáveis estão sendo substituídas por uma expansão urbana desordenada.

De acordo com os relatos, com relação ao uso doméstico da água nas décadas de 1950 a 1970, se lavava louças, roupas e se tomava banho direto no rio (em especial nas regiões mais altas). A água para beber era coletada diretamente no rio ou em poços rasos. A partir da década de 1980 foi encanada a água dos morros para abastecimento das casas e no centro o abastecimento era feito por poço artesiano ou água encanada. Nas décadas de 1950 a 1990 o esgoto não era tratado e eram construídas patentes no solo ou em cima do rio utilizadas como vaso sanitário. Somente a partir da década de 1990 foram construídos banheiros e fossas. Desde a década de 2000, todas as casas possuem banheiro e fossa, porém, de acordo com os entrevistados é evidente a poluição do Rio Camboriú, pois o município ainda não possui rede de coleta de esgotos e estação de tratamento (Tabela 3).

Tabela 3. Cronologia de usos relatados, usos perdidos e características do curso médio da bacia hidrográfica do rio Camboriú.

\begin{tabular}{|c|c|c|c|}
\hline Período & Usos relatados & Usos perdidos & Características \\
\hline Antes de 1950 & $\begin{array}{l}\text { - Irrigação } \\
\text { - Pesca (lambari, tainhota, cascudo, traíra, jundiá, } \\
\text { cará, corcunda, saguarú, robalo, cascudo, } \\
\text { camarão branco e siri azul) } \\
\text { - Banho higiênico } \\
\text { - Uso doméstico } \\
\text { - Despejo de esgoto } \\
\text { - Navegação }\end{array}$ & & $\begin{array}{l}\text { - Agricultura familiar } \\
\text { - Corte de madeira nativa } \\
\text { - Fauna (jacarés, lontras, } \\
\text { capivaras) e flora abundantes } \\
\text { - Rio com profundidades de } 3 \\
\text { a } 4 \mathrm{~m} \text {. }\end{array}$ \\
\hline 1950 a 1970 & $\begin{array}{l}\text { - Irrigação } \\
\text { - Pesca (lambari, tainhota, cascudo, traíra, jundiá, } \\
\text { cará, corcunda, saguarú, robalo, cascudo, } \\
\text { camarão branco e siri azul) } \\
\text { - Nado } \\
\text { - Uso doméstico } \\
\text { - Despejo de esgoto } \\
\text { - Navegação }\end{array}$ & $\begin{array}{l}\text {-Banho } \\
\text { higiênico }\end{array}$ & $\begin{array}{l}\text { - Agricultora familiar (redução) } \\
\text { - Agrotóxicos } \\
\text { - Corte de madeira nativa } \\
\text { - Fauna (jacarés, lontras, } \\
\text { capivaras) e redução da flora, } \\
\text { incluindo as matas ciliares } \\
\text { - } 3 \text { a } 4 \text { metros profundidade }\end{array}$ \\
\hline 1980 a 1990 & $\begin{array}{l}\text { - Irrigação } \\
\text { - Despejo de esgoto (fossa) }\end{array}$ & $\begin{array}{l}\text { - Pesca } \\
\text { - Nado } \\
\text { - Uso } \\
\text { doméstico }\end{array}$ & $\begin{array}{l}\text { - Rizicultura } \\
\text { - Insetos } \\
\text { - Pesque-pague } \\
\text { - Rio com profundidades de }\end{array}$ \\
\hline
\end{tabular}




\begin{tabular}{|c|c|c|c|}
\hline & & $\begin{array}{l}\text { - Extinção da } \\
\text { fauna e da flora } \\
\text { - Navegação }\end{array}$ & $30 \mathrm{~cm}$. \\
\hline 2000 até hoje & $\begin{array}{l}\text { - Irrigação } \\
\text { - Despejo de esgoto (fossa) }\end{array}$ & $\begin{array}{l}\text { - Pesca } \\
\text { - Nado } \\
\text { - Uso } \\
\text { doméstico } \\
\text { - Navegacão }\end{array}$ & \\
\hline
\end{tabular}

De acordo com os relatos, com relação ao uso doméstico da água nas décadas de 1950 a 1970, se lavava louças, roupas e se tomava banho direto no rio (em especial nas regiões mais altas). Devido as características ecológicas do curso médio, leito mais arenoso e menor velocidade da água, até a década de 1970, foi relatado que se tomava muito banho de rio, pois o rio era muito limpo e profundo e a água era muito transparente, a partir da década de 1980 o rio começa a ficar poluído. Havia pontos mais profundos, que chegavam a 3 ou até 4 metros devido aos meandros, que foram retificados. A partir da década de 1990, o rio começa a ficar assoreado, com uma profundidade que chega a até $30 \mathrm{~cm}$, provavelmente devido às retificações. A partir da década de 1990, o rio já está bastante poluído por esgotos e por agrotóxicos e não se toma mais banho nas áreas da planície. Segundo os entrevistados, hoje a água do rio é utilizada somente na rizicultura irrigada e para o despejo de esgotos sem tratamento adequado, o que tornou o rio morto, causando muita tristeza aos entrevistados. Ainda de acordo com os relatos, marmorarias do centro despejam resíduos no rio, poluindo muito.

Com relação à pesca nesta região, de acordo com os relatos, de 1950 a 1970 havia mais peixes nos rios e se pescava mais, pois o rio era mais caudaloso. Algumas espécies de peixes existentes eram: lambari, tainhota, cascudo, traíra, jundiá, cará, corcunda, saguarú, robalo, cascudo, camarão branco e ainda siri-azul em alguns locais. Se pescava com balaio, rede, caniço, tarrafa, covo (funil de taquara) e puçá. A partir da década de 1980, devido as retificações e dragagens, se percebe a gradativa redução dos peixes e da pesca e o aumento da quantidade de insetos. Nesta década, se inicia o funcionamento de pesque-pague no curso médio, introduzindo espécies exóticas. Segundo os entrevistados, a partir da década de 1990, ocorre a redução dos peixes devido a poluição.

Segundo as narrativas das entrevistas, na década de 1950, a agricultura era bastante desenvolvida, sendo que café, banana, farinha e mandioca eram as produções mais representativas, além de feijão, milho, melancia, cana, fumo e batata doce. Havia exploração de madeira e lenha, se criavam animais e se produzia ovo, manteiga, leite e queijo. A partir de 1960, começa o uso do agrotóxico, em especial no fumo e no arroz. Na década de 1970, são derrubados os cafezais e 
ocorre o desaparecimento da banana, devido ao preço baixo e inicia a expansão do arroz. A partir da década de 1990, o plantio de arroz é intensificado e a agricultura familiar gradativamente reduzida, devido ao êxodo rural. Atualmente a rizicultura continua sendo a atividade mais desenvolvida na região, porém em propriedades cada vez maiores. A agricultura familiar não é expressiva e o centro de Camboriú teve sua expansão urbana intensificada a partir da década de 2000.

Uma intervenção importante que também foi realizada no curso médio, foi a retificação do rio na década de 1980, da mesma maneira que no curso superior. Porém nessa área, além das retificações também foram feitas dragagens para aprofundamento do leito. Nessa área, de acordo com as entrevistas, os moradores também tiveram a percepção que a partir dessas modificações sumiram os peixes do rio. Como dito anteriormente, as curvas servem de refúgios para diversas espécies e facilitam a obtenção de alimentação para os peixes, além disso, hoje se sabe que as retificações não foram uma solução adequada para a redução das enchentes.

Nas décadas de 1950 a 1970, a população da zona rural do curso médio era maior que a de hoje, havia posto de combustíveis, companhia de cimento e bastante movimento no local, pois a estrada era utilizada para deslocamento intermunicipal. Com a construção da BR101, o movimento no local foi reduzido, reduzindo também o fluxo econômico, causando um êxodo rural e essa população gradativamente reduziu até a década de 1990. A partir última da virada de século, as pessoas começaram a retornar ao campo, porém com parcelamentos e loteamentos irregulares para moradia ou casa de campo. Este fluxo tem causado um crescimento desordenado da população, com uma urbanização descontrolada causada pelo êxodo urbano, que utiliza o campo como dormitório ou como casa de final de semana, pois essas pessoas permanecem trabalhando na cidade, pouco agregando a comunidade local.

Foi relatado que, na década de 1950 a 1960, havia bastante vegetação nativa, apesar de desmatamentos para plantios. A partir da década de 1970, foi visível a redução da vegetação nativa na região, incluindo as matas ciliares, devido aos plantios e à urbanização de áreas que anteriormente pertenciam à zona rural. $\mathrm{A}$ partir da década de 1990 as matas ciliares estão bastante desmatadas. Granemann (2014) encontrou 58\% de baixa densidade de vegetação e 14\% de ausência de vegetação das matas ciliares nos pontos avaliados no seu estudo das áreas rurais da bacia. Por outro lado, os relatos mostram que até a década de 1950 havia muitos 
jacarés, lontras, capivaras e muitos peixes nesta região do rio, sendo que a partir da década de 1960 eles foram gradativamente reduzindo e hoje várias espécies estão extintas e há pouquíssima fauna no rio. Até 1980 ainda havia navegação no rio Camboriú, com barcos pequenos e canoas para pesca e lazer. A partir da década de 1980, gradativamente o rio é assoreado, o que inviabiliza a navegação. Outro fato relatado, foi que até a década de 1980 o transporte de colheitas e de pessoas era, em sua maioria feito por carros de boi e carroças.

\section{Curso inferior}

De acordo com as entrevistas do curso inferior, com relação ao uso doméstico da água, nas décadas de 1950 a 1980, era feito da mesma maneira que no curso médio. A partir de 1970, foram construídos poços rasos, utilizados até a década de 1990 em algumas casas. Em alguns locais, somente a partir de 2000, foram instaladas redes de água encanada. Somente a partir da década de 1980 foram construídos os banheiros e muitos ainda despejavam o esgoto direto no rio até o início do século XXI. As fossas começaram a ser construídas somente a partir da década de 1990 e são o método de tratamento utilizado até hoje. Segundo as entrevistas, hoje, no bairro da Barra, somente aproximadamente $30 \%$ do bairro possui fossa, o restante é despejado diretamente no rio Camboriú. Com relação ao banho recreativo de rio, até a década de 1970 se tomava muito banho de rio, o rio era muito limpo e profundo e a água era muito transparente. A partir da década de 1980, o rio começa a ficar assoreado, provavelmente devido às retificações e a partir da década de 1990, o rio já está bastante poluído e não se toma mais banho no rio (Tabela 4).

Tabela 4. Usos relatados, usos perdidos e características do curso inferior da bacia hidrográfica do rio Camboriú em diferentes períodos.

\begin{tabular}{|c|c|c|c|}
\hline Período & Usos relatados & Usos perdidos & Características \\
\hline $\begin{array}{ll}\text { Antes } & \text { de } \\
1950 & \end{array}$ & $\begin{array}{l}\text { - Irrigação } \\
\text { - Pesca (cará, traíra, jundiá, piava, } \\
\text { papa terra, tainha, escrivão, robalo, } \\
\text { bagre, camarão e muitos siris) } \\
\text { - Pesca Barra (robalo, tainha, } \\
\text { corvina, cação, caranha, linguado, } \\
\text { camarão perereca, além de marisco } \\
\text { de mangue, berbigão, ostras e } \\
\text { caranguejo) } \\
\text { - Pesca lagoas (tainha, tainhota, } \\
\text { robalo, camarão e siris de garra azul) } \\
\text { - Banho higiênico } \\
\text { - Uso doméstico } \\
\text { - Despejo de esgoto } \\
\text { - Navegação }\end{array}$ & & $\begin{array}{l}\text { - Agricultura familiar } \\
\text { - Corte de madeira nativa } \\
\text { - Fauna e flora abundantes } \\
\text { - Profundidade lagoas (2 metros) }\end{array}$ \\
\hline 1950 a 1970 & $\begin{array}{l}\text { - Irrigação } \\
\text { - Pesca } \\
\text { - Nado } \\
\text { - Uso doméstico } \\
\text { - Despejo de esgoto } \\
\text { - Navegação }\end{array}$ & $\begin{array}{l}\text { - Lagoas (centro) } \\
\text { - Pesca } \\
\text { - Banho higiênico }\end{array}$ & $\begin{array}{l}\text { - Agricultora familiar (redução) } \\
\text { - Agrotóxicos } \\
\text { - Corte de madeira nativa } \\
\text { - Fauna e flora abundantes }\end{array}$ \\
\hline
\end{tabular}




\begin{tabular}{|c|c|c|c|}
\hline 1980 a 1990 & $\begin{array}{l}\text { - Irrigação } \\
\text { - Despejo de esgoto (fossa e ETE) }\end{array}$ & $\begin{array}{l}\text { - Pesca } \\
\text { - Nado } \\
\text { - Uso doméstico } \\
\text { - Extinção da fauna e da } \\
\text { flora } \\
\text { - Navegação }\end{array}$ & $\begin{array}{l}\text { - Rizicultura } \\
\text { - Aumento dos insetos }\end{array}$ \\
\hline $\begin{array}{l}2000 \quad \text { até } \\
\text { hoje }\end{array}$ & $\begin{array}{l}\text { - Irrigação } \\
\text { - Despejo de esgoto (fossa e ETE) }\end{array}$ & $\begin{array}{l}\text { - Pesca } \\
\text { - Nado } \\
\text { - Uso doméstico } \\
\text { - Navegação }\end{array}$ & - Especulação imobiliária \\
\hline
\end{tabular}

Segundo os relatos do Centro, até a década de 1950, em algumas casas, se puxava a água de ribeirões. Na década de 1960, foram construídos poços rasos e também foi iniciada a instalação da rede de água encanada. Na década de 1980, também se utilizavam poços artesianos. Até a década de 1960, o esgoto era despejado diretamente nos córregos, nas lagoas, no rio e no mar. A partir de 1970, foram construídas fossas, mas muito esgoto ainda era despejado nos cursos de água sem tratamento. A partir da década de 1980, a rede de coleta e a estação de tratamento de efluentes começaram a ser construídas. Atualmente todo o centro do município e a maioria dos bairros possuem rede de coleta e estação de tratamento de esgotos (ETE), porém está mal dimensionada e é ineficiente de acordo com os relatos das entrevistas.

Segundo as entrevistas, no bairro da Barra, até a década de 1970, o mangue que protegia o rio estava preservado. O rio era muito limpo, a água era transparente e o leito era de areia branca. A partir da década de 1980, o banho de rio foi reduzido devido à poluição. A partir da década de 1990, houve a piora gradativa da qualidade da água e não teve mais como se tomar banho de rio. Os entrevistados afirmaram ainda que atualmente, o rio foi bastante dragado, a água é preta, lamosa, com lodo até o joelho, um esgoto puro, sem peixes, sem caranguejos e não se toma mais banho no rio.

Antes da década de 1950, as pessoas tomavam banho de mar terapêutico, indicado para algumas doenças. Nas décadas de 1950 e 1960, se tomava banho para higiene pessoal no rio, nos córregos e nas lagoas. Até a década de 1970, o rio era mais profundo e muito limpo e tomava-se muito banho nas lagoas de Balneário. A água das lagoas era muito limpa e transparente e a profundidade chegava a dois metros, havia uma areia muito branca e bastante vegetação no entorno das mesmas, até onde hoje se localiza a avenida Brasil (segunda quadra do mar). A partir da década de 1980, as lagoas viraram esgoto a céu aberto, foram tubuladas e aterradas. Nesta década, ainda se tomava muito banho no rio, que era limpo.

Com relação à pesca nesta área foram relatados os seguintes peixes nas décadas de 1950 e 1960: cará, traíra, jundiá, piava, papa-terra, tainha, escrivão, 
robalo, bagre, camarão e muitos siris. Também foi relatado que a água era muito limpa e a pesca artesanal era muito desenvolvida. A partir de 1960, já era raro conseguir pescar o robalo grande, e a partir da década de 1970, os peixes foram diminuindo, sendo que atualmente quase não há pesca. Hoje os rios nessa região estão bastante poluídos e com águas praticamente transformadas em esgoto bruto. No bairro da Barra, até a década de 1970 ainda se pescava robalo, tainha, corvina, cação, caranha, linguado, camarão perereca, além de marisco de mangue, berbigão, ostras e caranguejo. Moradores afirmam que se caçava caranguejos no mangue, também como diversão dos jovens. As ostras eram pescadas no Rio das Ostras, que hoje nada mais é que esgoto a céu aberto. As embarcações chegavam lotadas de peixes, o bairro era uma vila de pescadores. O petrecho de pesca mais utilizado era tarrafa. A partir da década de 1980, com a poluição, a expressividade da pesca começa a diminuir. Na década de 1990, foi a última vez que se teve um grande lance de camarão no rio Camboriú, depois disso, com as dragagens nunca mais se pescou camarão e a quantidade de peixes ficou bastante reduzida. Atualmente, moradores relatam que o número de espécies encontradas no rio diminuiu e pescase somente para vender, pois quem pesca não tem coragem de comer. Em adição, houve o relato que a redução dos peixes na Barra está associada ao crescimento da indústria pesqueira, pois os peixes são pescados em alto mar e não chegam no rio.

Segundo as entrevistas, com relação à agricultura, até a década de 1970, ela era muito desenvolvida, com a produção de mandioca, cana, feijão milho, arroz, café e corte de madeira. No bairro São Francisco, havia seis engenhos de farinha. Havia também a extração de pedra pelos broqueiros, em especial, o granito. A partir da década de 1980, a agricultura é gradativamente reduzida devido ao êxodo rural e atualmente devido a outros fatores, entre eles, a especulação imobiliária.

Até a década de 1960, a agricultura era desenvolvida em alguns sítios de Balneário Camboriú, localizados mais próximos à divisa com Camboriú, em especial as culturas de mandioca, café, banana, cana, feijão, milho e hortas. Na década de 1960, entre a terceira e quarta avenida, havia muitos pomares, chácaras e sítios que foram se extinguindo até a década de 1970. Atualmente o município de Balneário Camboriú não possui zona rural em seu plano diretor e nenhuma atividade agrícola que seja expressiva.

Até 1950 ainda havia navegação no rio Camboriú, com grandes barcos a vela que chegavam aos portos existentes. O rio era mais largo e mais profundo. Segundo as entrevistas, a partir da década de 1960, o rio inicia a redução do seu calado com 
o assoreamento e a navegação é inviabilizada em alguns locais, a partir de 1990, somente pequenos barcos e canoas tem a possibilidade de navegarem rio acima. No bairro da Barra, até a década de 1970, a navegação era feita com barcos à vela, pedalinhos, caiaques e bateras a remo. A partir de 1980, começam as navegações com jet-skis, barcos a motor, e lanchas. Nesta década foram inauguradas marinas, que desenvolveram a navegação a motor no bairro. A partir de 2000, foram intensificadas as dragagens no rio, favorecendo a navegação a motor. Anteriormente às dragagens na foz do rio Camboriú, se atravessava o rio a pé na maré baixa, 0 fundo era arenoso e a água muito limpa. Hoje, além de profundo, o fundo do rio é muito lamoso (com lodo até o joelho), devido ao esgoto.

Até a década de 1960, um barco com dez toneladas de cal navegava entrando desde o mar no rio Marambaia, continuando pelos rios Saracura (hoje rua 600) e Peroba, chegando ao rio Camboriú até o centro de Camboriú atual. A partir dessa década já é evidente o assoreamento do rio, devido a construções, despejo de esgotos e intensa mineração no município de Camboriú durante décadas. No centro de Balneário, até a década de 1970, navegava-se muito de canoa nas lagoas e ribeirões para passeio e pesca. Havia muitos canais que desaguavam no mar: rua $51,951,600,2700$, canal do Marambaia e pelo rio Peroba ainda se chegava até Camboriú, mesmo com o assoreamento intensificado nessa década. A partir da década de 1980, as lagoas viraram esgoto a céu aberto, foram tubuladas e aterradas, ficando o rio ficou cada vez mais assoreado. A partir da década de 1990, somente barcos pequenos e canoas navegam o Canal do Marambaia, único afluente que sobrou na região central de Balneário Camboriú.

$\mathrm{Na}$ foz pode ser observada a intensa urbanização e verticalização ao longo do tempo ao norte do rio Camboriú e a estagnação do crescimento no bairro da Barra, localizado ao sul do rio Camboriú. De acordo com Schaefer (2016), o rio Camboriú foi um divisor social entre um bairro que não obteve a mesma atenção dos governantes da cidade, em detrimento daquele que cresceu a sua frente. $O$ bairro da Barra possui hoje uma comunidade tradicional, tendo uma herança cultural baseada na atividade pesqueira como característica principal, que merece ter resgatados alguns traços de sua identidade e ter a mesma valorizada pelo poder público e por toda a comunidade da bacia. A Barra apresenta edificações baixas e mantém os contornos da serra e outros elementos naturais presentes, diferindo drasticamente da paisagem da margem norte do rio, onde a verticalização dos edifícios e a urbanização da planície litorânea desconfiguraram as relações do ambiente 
construído com o ambiente natural. No bairro da Barra, ainda hoje o rio e as montanhas marcam o dia-a-dia da população (Schaefer, 2016).

O centro de Balneário Camboriú é um local que exerce uma grande pressão no rio, devido à concentração populacional e um elevado crescimento urbano num curto espaço de tempo, foi um local de grandes modificações. Até a década de 1970, pescava-se bastante nos afluentes do rio Camboriú e nas lagoas (hoje inexistentes) localizados na praia de Balneário Camboriú, as principais espécies eram tainha, tainhota, robalo, camarão e siris de garra azul. Também se pescava ostra próximo à antiga ponte suspensa de madeira, no Bairro Vila Real. O último grande lance de tainha na praia foi em 1973, após isso, com o fortalecimento da pesca industrial, a pesca artesanal ficou decadente. A partir da década de 1980, as lagoas e os afluentes do centro viraram esgoto a céu aberto, foram tubuladas ou aterradas.

A concentração da urbanização e a intensa verticalização das últimas décadas foram pontos bastante citados nos relatos. Em estudo desenvolvido por Piatto e Polette (2012), os autores encontraram a predominância do considerado Alto Nível de Artificialização no centro de Balneário Camboriú. Essa artificialização, baseada na verticalização, que concentra um grande número de pessoas num pequeno espaço, trouxe consigo problema ambientais, de infraestrutura e de planejamento. O aumento acelerado da população esgotou a capacidade de suporte da orla marítima, saturando o centro urbano em inúmeros aspectos como: trânsito caótico, indisponibilidade de água, poluição dos cursos de água e da praia e número imóveis insuficientes. Essa saturação da capacidade de suporte do centro de Balneário levou as regiões periféricas ao mesmo intenso processo de artificialização, como é o caso do município de Camboriú (Piatto e Polette, 2012).

Outro fenômeno que ocorreu na região e começou por Balneário Camboriú foi a gentrificação, que segundo Bataller (2012), é um processo fundamentalmente urbano e que consiste na realização de melhorias físicas ou materiais e mudanças imateriais, econômicas, sociais e culturais, que ocorrem em alguns bairros centrais, históricos, ou com potencial turístico, os quais experimentam uma apreciável elevação de seu status. A mesma caracteriza-se normalmente pela ocupação dos centros das cidades por uma população de renda mais elevada, que desloca os habitantes de renda mais baixa, que viviam no centro urbano (Schaefer, 2016; Bataller, 2012). 


\section{Considerações Finais}

Até a década de 1970, apesar das modificações sofridas na bacia hidrográfica do rio Camboriú, relatadas nas entrevistas e identificadas na pesquisa histórica, a mesma permanecia relativamente intacta, sem degradação perceptível da qualidade ambiental e, em especial, dos recursos hídricos. A partir da década de 1980, com elevado crescimento populacional das áreas urbanas, aumento do fluxo turístico, urbanização crescente, tubulação de afluentes, falta de tratamento adequado dos efluentes e aterramento de lagunas, a degradação da qualidade dos recursos hídricos ficou evidente. Além do processo de degradação ambiental acentuado nos últimos 30 anos, a atual falta de tratamento de efluentes em Camboriú e insuficiente em Balneário Camboriú, resultou em uma qualidade ambiental comprometida, tanto no curso médio quanto inferior do rio Camboriú (Antunes et al., 2007; Urban, 2008; Padilha, 2013).

Apesar da boa qualidade da água no curso superior, a redução da quantidade de água disponível foi bastante citada pelos entrevistados e deve ser vista com preocupação. O limite de segurança para o atendimento de abastecimento público de água na bacia hidrográfica do rio Camboriú está projetado entre os anos de 2024 e 2033, considerando um cenário tendencial, que inclui a construção de reservatório (Granemann e Espinosa, 2013). Desta forma, são necessários projetos para assegurar essa demanda futura, podendo incluir construção de reservatórios de água bruta e preservação/recuperação das matas ciliares (Brognoli, 2010; Granemann, 2014; Silva, 2015).

A obtenção de relatos de memórias mostra-se como um instrumento robusto para a identificação de processos de degradação ambiental ao longo de décadas em bacias hidrográficas. As similaridades dos relatos dos entrevistados, de diferentes locais e idades, revelam uma descrição fidedigna da realidade dos eventos ocorridos. Ao mesmo tempo, as perdas na qualidade ambiental da bacia hidrográfica do rio Camboriú causaram cicatrizes irreparáveis, não compensadas por ganhos econômicos e aumento do poder aquisitivo, fato observado em outros estudos (Lopes e Nodari, 2012; Camargo, 2016; Sartori e Valencio, 2016). A percepção de antigos moradores sobre o passado, o presente e anseios futuros, pode melhorar a gestão dos recursos hídricos em uma bacia hidrográfica, pois encontra respaldo da comunidade local para implementação de ações necessárias na bacia (Almeida, 2003; Rodrigues et al., 2012; Antunes et al., 2014; Sartori e Valencio, 2016; Garcia, 2017). 


\section{REFERÊNCIAS}

ALANOCA, V.; APAZA, J. Saberes de protección ambiental y discriminación en las comunidades de aymaras de llave. Revista de Investigaciones Altoandinas, v. 20, n. 1, p. 95-108, 2018.

ALMEIDA, R.C. A memória dos idosos como instrumento de avaliação dos impactos da urbanização sobre os recursos hídricos. In.: Felicidade, N.; Martins, R.C.; Leme, A.A., Uso e gestão dos recursos hídricos no Brasil. São Carlos, p.39-53, 2001.

ANJOS, F. A.; VIANA, L. J. T.; LOPES, E. B. La organización del espacio público y privado en área central del sistema turístico: El caso de la aglomeración urbana Itajaí-Balneário Camboriú, Santa Catarina, Brasil. Estudios y perspectivas en turismo, v.18, n.5, p.588605, 2009.

ANTUNES, A.; SCHWINGEL, P. R.; BURLIGA, A. L. M.; URBAN, S. Composição do fitoplâncton na bacia hidrográfica do rio Camboriú (SC-Brasil) durante o verão de 2005. Brazilian Journal of Aquatic Science Technology, v. 11, n. 2, p.33-43, 2007. ANTUNES, C. M. M.; BITTENCOURT, S. C.; RECH, T. D.; OLIVEIRA, A. C. Qualidade das águas e percepção de moradores sobre um rio urbano. Revista Brasileira de Ciências Ambientais, n.32, 2014.

APARICIO, A. T.; CANALES, P. J. H. Gestión de riesgos y desastres socioambientales. El caso de la mina Buenavista del cobre de Cananea. Investigaciones geográficas, n. 93, 2017.

BATALLER, M. A. S. O estudo da Gentrificação. Revista Continentes, v.1, n.1, 2012.

BROCANELI, P. F.; STUERMER, M. M. Renaturalização de rios e córregos no município de São Paulo. Exacta, v. 6, n. 1, p. 147-156, 2008.

BROGNOLI, F. F. Proposta de implantação de um parque inundável multiuso na bacia do Rio Camboriú. Monografia (Pós-graduação) - Curso de Gerenciamento de Águas e Efluentes, Faculdade de Tecnologia SENAI, Blumenau, 2010.

CAMARGO, F. M. La historia ambiental urbana: contexto de surgimiento y contribuciones para el analisis historico de la ciudad. Anuario Colombiano de Historia Social y de la Cultura, v. 43, n.1, p.375-402, 2016.

CECHET, M. J. Diagnóstico dos aspectos de uso do solo nas propriedades rurais de Camboriú, SC. Trabalho de Conclusão de Curso (graduação) - Curso de Engenharia Ambiental, Universidade da Vale do Itajaí, Itajaí, 2015.

CORRÊA, I.B. História de duas cidades: Camboriú e Balneário Camboriú. Ed. do autor. 1985.

CORRÊA, I.B. Dicionário Catarinense - Tratado de dialetologia, falares, subfalares e expressões idiomáticas no Estado Barriga Verde. Itajaí: Alternativa. 2012.

DEVOS, R.V.; SOARES, A.P.N.; ROCHA, A.L.C. Habitantes do Arroio: a memória ambiental das águas urbanas. Desenvolvimento e Meio ambiente, n.22, p 51-64, 2010.

DIEGUES, A.C. O mito da natureza intocada. São Paulo: Hucitec, 1998.

DUVAL, V. S. Análisis temporal de la actual configuración espacial de áreas protegidas de la provincia de La Pampa. Revista Universitaria de Geografía, v. 26, n. 2, p. 11-35, 2017. FARIA, I.M. et al. Vozes e imagens do Rio São Francisco: um estudo sobre populações tradicionais e problemas ambientais. In: BRUMER, A.; PIÑEIRO, D. (Org.). Agricultura latino-americana: novos arranjos e velhas questões. Porto Alegre: Ed. da UFRGS, p. 259-286, 2005.

GALEANO, E. As Veias Abertas da América Latina. Título original: Las venas abiertas de America Latina. Tradução Helena Pitta. Prefácio Júlio Henriques. Ed. Antigona. 1. a edição. Lisboa. 2017.

GARCÍA, S. B. De montaña, milpa y cañaveral. Transformaciones percibidas de los paisajes en la costa de Chiapas. Investigaciones geográficas, n. 93, 2017.

GRANEMANN, A. R. B.; ESPINOSA, H. R. M. Horizonte temporal do uso dos recursos hídricos na bacia hidrográfica do Rio Camboriú-SC, Brasil. XX Simpósio Brasileiro De Recursos Hídricos, 2013. 
GRANEMANN, A. R. B. Estudo das áreas de preservação permanente dos afluentes da Bacia Hidrográfica do Rio Camboriú (SC) frente a legislação vigente. Monografia (Pósgraduação) Curso de Especialização em Direito Ambiental, Universidade da Vale do Itajaí, Itajaí, 2014.

HALBWACHS, M. A memória coletiva. São Paulo: Centauro, 2006.

IBGE. Instituto Brasileiro de Geografia e Estatística. 2017. Dados: Santa Catarina.

Disponível em: www.ibge.gov.br. Acesso em: 05 de julho de 2017.

LOPES, A.R.S.; NODARI, E.S. Dossiê: História, natureza, cultura e oralidade. História Oral, v.1, n.15, p. 55-80, 2012.

McNEILL, J. Observations on the Nature and culture of environmental history. History and Theory, v. 42, p. 5-43, 2003.

MONTALBA, R.; VIELI, L.; VALLEJOS-ROMERO, A.; ZUNINO, H.; VERA, L. Determinación de las fuerzas conductoras de la transformación ambiental de la araucanía chilena: el "paisaje cultural" como marco de análisis. Diálogo andino, n. 54, p. 51-61, 2017.

MORAES, S. T.; TRICÁRICO, L. T. História, cultura e projeto urbano: a barra do rio Camboriú. Revista Paranaense de Desenvolvimento, v. 111, p. 105-127, 2006.

OKUMURA, M. Populações Sambaquianas Costeiras: saúde e afinidades biológicas dentro de um contexto geográfico e temporal. Tempos Acadêmicos, v. 11, 2013.

PADILHA, L. R. Modelagem da qualidade da água na Bacia Hidrográfica do Rio Camboriú/SC: Subsídios à gestão integrada dos recursos hídricos. Trabalho de Conclusão de Curso (graduação) - Curso de Engenharia Ambiental, Universidade da Vale do Itajaí, Itajaí, 2013.

PIATTO, L.; POLETTE, M. Análise do processo de artificialização do município de Balneário Camboriú, SC, Brasil. Journal of Integrated Coastal Zone Management, v. 12, p. 77-88, 2012.

POLLAK, M. Memória e identidade social. Revista Estudos Históricos, Rio de Janeiro, v. 5, n. 10, p. 200-212, 1992.

POTT, C. M.; ESTRELA, C. C. Histórico ambiental: desastres ambientais e o despertar de um novo pensamento. Estudos Avançados, v. 31, n. 89, p. 271-283, 2017.

REBELO, J.A. Sem história não dá; e assim se fez em Camboriú. Ed. do Autor. 1997. $328 p$.

REIS, A. F. Forma Urbana, Paisagem e Meio Ambiente: Estudo dos Processos de Crescimento Urbano-Turístico no Litoral Catarinense. X Colóquio Internacional de Geocrítica. Barcelona, Espanha. Disponível em: http://www.ub.edu/geocrit/-xcol/194.htm. Barcelona, 2008.

RIBEIRO, D. O povo brasileiro: a formação e o sentido do Brasil. Global Editora e Distribuidora Ltda., 2015.

RODRIGUES, A. S. L.; CASTRO, P. T. A.; MALAFAIA, G. Utilização dos protocolos de avaliação rápida de rios como instrumentos complementares na gestão de bacias hidrográficas envolvendo aspectos da geomorfologia fluvial: uma breve discussão. Enciclopédia Biosfera, vol.6, n.11, 2010.

RODRIGUES, M. L.; MALHEIROS, T. F.; FERNANDES, V.; DARÓS, T. D. A percepção ambiental como instrumento de apoio na gestão e na formulação de políticas públicas ambientais. Saúde e Sociedade, v. 21, p. 96-110, 2012.

SARTORI, J.; VALENCIO, N. O desastre vivenciado: a importância da memória social de idosos através da análise do caso de São Luiz do Paraitinga. Revista Pós Ciências Sociais, v. 13, n. 26, p. 181-214, 2016.

SCHAEFER, M. M. Análise Histórica. In: GALLARZA, G. (coord.) Retratos do Camboriú: paisagem cultural do rio Camboriú. Fundação Cultural de Balneário Camboriú, p.14-22, 2016.

SERPA, I. C. Os índios Xokleng em Santa Catarina: uma abordagem a partir da relação pesquisa, ensino e extensão no Instituto Federal Catarinense. Blumenau: IFC, 2015. SILVA, D. D. P. Caracterização ambiental dos principais afluentes da bacia hidrográfica do rio Camboriú (SC). Trabalho de Conclusão de Curso (graduação) - Curso de Engenharia Ambiental, Universidade da Vale do Itajaí, Itajaí, 2015. 
SKALEE, M.; REIS, A. F. Crescimento urbano-turístico: traçado e permanências urbanas em Balneário Camboriú. Scripta Nova: Revista electrónica de geografia y ciencias sociales, v.12, n. 270, 2008.

SKLENICKA, P., KOTTOVÁ, B., \& ŠÁLEK, M. Success in preserving historic rural landscapes under various policy measures: Incentives, restrictions or planning?

Environmental Science \& Policy, v. 75, p. 1-9, 2017. URBAN, S. R. Uso do solo na bacia hidrográfica do rio Camboriú (SC) e sua influência sobre a qualidade da água. Dissertação (Mestrado) - Curso de Ciência e Tecnologia Ambiental, Universidade da Vale do Itajaí, Itajaí, 2008.

VILLASEÑOR, A. T. The Annales School and the Environmental History of Latin America.

Historia Caribe, v. 12, n. 30, p. 301-340, 2017.

WEBBER, D. C. Subsídios para o enquadramento da bacia hidrográfica do rio

Camboriú, SC, Brasil. Dissertação (Mestrado) - Curso de Ciência e Tecnologia Ambiental, Universidade da Vale do Itajaí, Itajaí, 2010.

\section{NOTAS DE AUTOR}

\section{CONTRIBUIÇÃO DE AUTORIA}

Letícia Rabelo - Concepção, coleta de dados, análise de dados, elaboração do manuscrito, participação ativa da discussão dos resultados, revisão e aprovação da versão final do trabalho.

Paulo Ricardo Schwingel - Concepção, análise de dados, elaboração do manuscrito, participação ativa da discussão dos resultados, revisão e aprovação da versão final do trabalho.

\section{FINANCIAMENTO}

Instituto Federal Catarinense, bolsa/taxa CAPES Univali.

\section{CONSENTIMENTO DE USO DE IMAGEM}

Não se aplica

\section{APROVAÇÃO DE COMITÊ DE ÉTICA EM PESQUISA}

Não se aplica.

\section{CONFLITO DE INTERESSES}

Não se aplica.

\section{LICENÇA DE USO}

Este artigo está licenciado sob a Licença Creative Commons CC-BY. Com essa licença você pode compartilhar, adaptar, criar para qualquer fim, desde que atribua a autoria da obra.

\section{HISTÓRICO}

Recebido em: 08-12-2017

Aprovado em: 25-08-2019 